\title{
Epidemiological investigation for brucellosis in dogs of Thrissur ${ }^{\#}$
}

\author{
K. Athira*1, V. H. Shyma², K. D. Justin², K. Vijayakumar ${ }^{3}$ and C. Jayakumar ${ }^{4}$ \\ Department of Veterinary Epidemiology and Preventive Medicine, \\ College of Veterinary and Animal Sciences, Mannuthy- 680 651, Thrissur, Kerala \\ Kerala Veterinary and Animal Sciences University, Pookode, Wayanad, India.
}

Citation: Athira, K., Shyma, V. H., Justin, K. D., Vijayakumar, K. and Jayakumar, C. 2021. Epidemiological investigation for brucellosis in dogs of Thrissur. J. Vet. Anim. Sci. 52(4): 389-392 DOI: https://doi.org/10.51966/jvas.2021.52.4.389-392

Received: 14.03.2021

Accepted: 19.05.2021

Published: 15.12.2021

\begin{abstract}
India is endemic to bovine brucellosis, and there is a high potential for transmission of disease from ruminants to dogs. A total of 18 bitches belonging to five different breeds at different stage of abortion (30 days to 65 days of gestation) were selected for this study. Majority of them were showing abortion (88.89 per cent) at 45 to 65 days of the gestation. Microscopic examination of Stamp stained smear obtained from the aborted foetal stomach contents revealed red coccobacillary organisms suggestive of Brucella spp.in three cases. RBPT on paired sera samples on day of presentation and three weeks after abortion showed agglutination within four minutes in five out of 18 female dogs. DNA extracted from the aborted tissues of a RBPT positive Labrador dog yielded amplicons of 193 base pair specific for Brucella spp. on PCR. The results obtained from this study stress the need for screening dogs for canine brucellosis in the current brucellosis surveillance and control programmes.
\end{abstract}

Keywords: Bovine brucellosis, abortion, zoonotic disease, stamp staining, RBPT, PCR

Running title: Epidemiological investigation for brucellosis in dogs of Thrissur

Canine brucellosis is an infectious disease of dogs caused by Brucella spp. (B. canis, $B$. abortus, B. suis and B. melitensis) (Wanke, 2004). Hollett (2006) opined that canine brucellosis is one of the major causes of abortion and infertility in dogs and possessed a potential health hazard to humans. The Center for Food Security and Public Health (CFSPH, 2018) reviewed that canine brucellosis could end the reproductive life of a breeding animal. The present study was carried out realising the importance of diagnosing a zoonotic disease in the current pandemic situation and paucity of information on canine brucellosis in Kerala.

"Forms part of the MVSc thesis submitted by the first author to the Kerala Veterinary and Animal Sciences University, Pookode, Wayanad, Kerala.

1. MVSc Scholar and *Corresponding author, email ID: athirasonukondath@gmail.com, Ph: 8281327732

2. Assistant Professors

3. Professor and Head

4. Assistant Professor, Department of Animal Reproduction Gynaecology and Obstetrics

Copyright: (c) 2021 Athira et al. This is an open access article distributed under the terms of the Creative Commons Attribution 4.0 International License (http://creativecommons.org/licenses/by/4.0/), which permits unrestricted use, distribution, and reproduction in any medium, provided the original author and source are credited. 


\section{Materials and methods}

A total of 18 female dogs with a history of abortion at different stages of gestation presented to the University Veterinary Hospitals, Kokkalai and Mannuthy were selected for this study.

On the day of presentation, impression smears from foetal stomach contents were collected and examined by stamp staining method (Alton et al., 1988). Paired serum samples were collected from selected animals on the day of presentation and after 3 weeks of abortion for serological studies using Rose Bengal plate test (RBPT).

Stomach contents of aborted foetus and post abortion vaginal discharges collected in sterile containers was used for extraction of Deoxyribonucleic acid (DNA). Brucella genus specific polymerase chain reaction (PCR) was performed from the extracted DNA samples using the forward primer (JPF) sequence (5'-GCGCTCAGGCTGCCGACGCAA-3') and the reverse primer (JPR) sequence (5'AC CAGCCATTGCGGTCGGTA-3'), at a denaturation temperature of $94^{\circ} \mathrm{C}$ for 4 minutes, followed by 35 cycles at $94^{\circ} \mathrm{C}$ for 60 seconds, $60^{\circ} \mathrm{C}$ for 60 seconds, and $72^{\circ} \mathrm{C}$ for 60 seconds and one final extension at $72^{\circ} \mathrm{C}$ for 3 minutes (Leal-Klevezas et al.,1995).

\section{Results and discussion}

Canine brucellosis holds the nickname, "The Great Imposter" (Bramlage et al., 2015), because the clinical signs of infection could mimic many other diseases. In India, the first report of Brucella infection in dogs was that of Pillai et al. (1991) from Small Animal Clinic of the Madras Veterinary College, Chennai.

Behzadi and Mogheiseh (2011) reported that all breeds of sexually mature, reproductively active dogs are equally infected by Brucella spp. In this study, 18 bitches of five different breeds (Labrador, Rottweiler, Beagle, Spitz, German shepherd dog) at different stage of abortion (30 days to 65 days of gestation) were included. Majority of the abortions (88.89 per cent) were mid to late term (45 to 65 days) of the gestation as described by Wanke (2004) for canine brucellosis (Fig. 1).

The Stamp stained smears obtained from the aborted foetal stomach contents on microscopic examination revealed red coccobacillary organisms against the blue background suggestive of Brucella spp. in three cases.

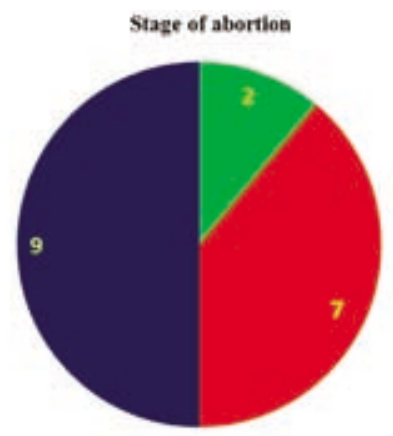

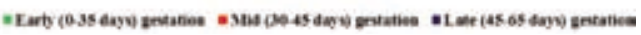
Fig. 1. Stage of abortion in dogs with history of abortion

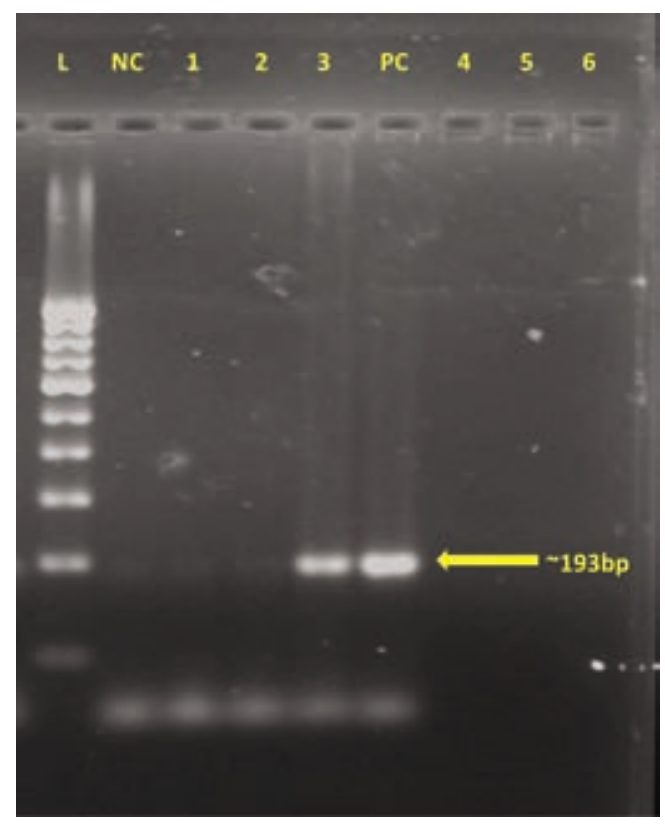

Fig. 2. Agar gel electrophoresis of genus specific PCR of Brucella spp. (L- Lane, 100 bp ladder; NC - Negative control; PC- Positive control)

Baek et al. (2003) suggested RBPT as the main serological screening test for the diagnosis of brucella infection in suspected dogs with history of abortion. Out of 18 paired serum samples collected, five samples $(27.78$ 
per cent) showed agglutination on RBPT using $B$. abortus $\mathrm{S} 99$ antigen within four minutes.

Brucella genus specific PCR was performed as described by Leal-Klevezas et al. (1995), which yielded an amplicon size of 193 base pair (Fig. 2). Thus, Brucella infection could be confirmed from the DNA samples extracted from the uterine discharges of a RBPT positive Labrador dog.

Canine brucellosis should be considered in the differential diagnosis whenever there is a history of abortion in female dogs (Carmichael, 2018). Cosford (2018) recommended that all male and female dogs should be routinely tested serologically before mating. In brucella tested positive cases, it is advised to neuter or castrate such dogs even though they are of high genetic value. Alamian and Dadar (2020) stressed the need for systematic screening and epidemiological investigations on canine brucellosis among companion animals in order to improve brucellosis surveillance and control programs. Mol et al. (2020) clearly demonstrated that the diagnosis of canine brucellosis remained a challenge even when multiple tests were employed.

In this study, a combination of RBPT and PCR, which is an easy, economic and reliable technique helped in proper diagnosis of the case.

\section{Conclusion}

To conclude, all dogs of reproductive age should be regularly screened for brucellosis. All urogenital infections in animals should be treated with antibiotics only if required and should be in accordance with the culture and sensitivity pattern of antibiotics. Animals tested positive for brucella infection should not be used for further breeding purposes.

\section{Acknowledgement}

The authors are thankful to authorities of Kerala Veterinary and Animal Sciences University for providing all facilities for the completion of this work.

\section{Conflict of interest}

The authors declare that they have no conflict of interest.

\section{References}

Alamian, S. and Dadar, M. 2020. Brucella melitensis infection in dog: a critical issue in the control of brucellosis in ruminant farms. Comp. Immunol. Microbiol. Infect. Dis. 73: 1-5. Available: https://www. sciencedirect.com/science/article/pii/ S0147957120301430. [7 Mar. 2021].

Alton, G. G., Jones, L. M., Angus, R. D., Verger, J.M. 1988. Techniques for the brucellosis laboratory. ( $1^{\text {st }}$ Ed.). Paris: Institut National de la Recherche Agronomique. 192p.

Baek, B. K., Lim, C.W., Rahman, M. S., Kim, C., Oluoch, A. and Kakoma, I. 2003. Brucella abortus infection in indigenous Korean dogs. Canad. J. Vet. Res. 67: 312- 314.

Behzadi, M. A. and Mogheiseh, A. 2011. Epidemiological survey of Brucella canis infection in different breeds of dogs in Fars province, Iran. Pak. Ve.t J. 32: 234236.

Bramlage, D. J., Fortney, W., Kesler, R. M. 2015. Best Practices for Brucella canis Prevention and Control in Dog Breeding Facilities. United States Department of Agriculture Animal and Plant Health Inspection Service. 2p.

Carmichael, L. E. 2018. Brucella canis. In: Nielsen, K. and Duncan, J. R. (ed.), Animal Brucellosis. (1 ${ }^{\text {st }}$ Ed.). CRC Press, Taylor \& Francis group, London, pp. 335350.

Cosford, K. L. 2018. Brucella canis: An update on research and clinical management. Can. Vet. J. 59:74-81

Hollett,R.B.,2006.Caninebrucellosis:outbreaks and compliance. Theriogenology. 66: 575-587. 
Leal-Klevezas, D. S., Martinez-Vaquez, I. O., Lopez-Merino, A. and Martinez-Soriano, J. P. 1995. Single-step PCR for detection of Brucella spp. from blood and milk of infected animals. J. Clin. Microbiol. 33: 3087-3090.

Mol, J. P., Guedes, A.C., Eckstein, C., Quintal, A. P., Souza, T. D. et al. 2020. Diagnosis of canine brucellosis: comparison of various serologic tests and PCR. J. Vet. Diagn. Invest. 32:77-86.

Pillai, M. T., Nedunchelliyan, S. and Raghavan, N. 1991. Serological and bacteriological detection of Brucella canis infection of dogs in Madras. Indian Vet. J. 68: 399401.

The centre for food security and public health. 2018. Canine brucellosis: Brucella canis. lowa State University, Ames, lowa.10p. Available: https://www.cfsph.iastate. edu/Factsheets/pdfs/brucellosis_canis. pdf

Wanke, M. M. 2004. Canine brucellosis. Anim. Reprod. Sci. 82-83: 195 -207. 